\title{
Static Adhesion Assay for Human Peripheral Blood Mononuclear Cells
}

Giulia Vanoni ${ }^{1}, \$, *$, Camilla Jandus ${ }^{2, \#}$ and Sara Trabanelli ${ }^{2, ~ \# ~}$

${ }^{1}$ Department of Oncology, Ludwig Institute for Cancer Research - University of Lausanne, Lausanne, Switzerland

2Department of Pathology and Immunology, Faculty of Medicine, University of Geneva, Geneva, Switzerland

\$Current address: INSERM U932, Institut Curie, PSL Research University, Paris, France

*For correspondence: giulia.vanoni@curie.fr

\#Contributed equally to this work

[Abstract] Blood endothelial cells (ECs) constitute the primary physical barrier to be crossed by circulating leukocytes, once attracted to a site of ongoing inflammation/infection. Upon a proinflammatory stimulus, such as tumor necrosis factor (TNF), ECs upregulate adhesion molecule expression to favor the adhesion and, subsequently, the transendothelial migration of the attracted lymphocytes. To address the ability of a cell to transmigrate through a monolayer of ECs, the classical transmigration assay is usually performed (Muller and Luscinskas, 2008). In the present protocol, adapted from Safuan et al. (2012), we describe an in vitro assay for assessing the functionality of the second step of the transendothelial migration, i.e., the firm adhesion of peripheral blood mononuclear cells (PBMCs) to ECs, under static conditions. By pre-incubating primary human umbilical cord ECs (HUVECs) with either innate lymphoid cell progenitors (ILCPs) or TNF, we were able to upregulate adhesion molecules on the EC surface. Then, by adding total PBMCs, we were able to both quantitatively and qualitatively analyze the cellular subtype and number of PBMCs that adhered to the pre-treated ECs. The important advantage of this technique is the possibility to perform functional studies on ECs biology since, differently from transwell-based strategies, it allows a good recovery of ECs at the end of the assay. Overall, this assay enables to interrogate how/if different stimulations/cell types can influence EC ability to retain PBMCs in vitro, under static conditions. 


\section{Graphic abstract:}

\section{STATIC ADHESION ASSAY}

Day 1

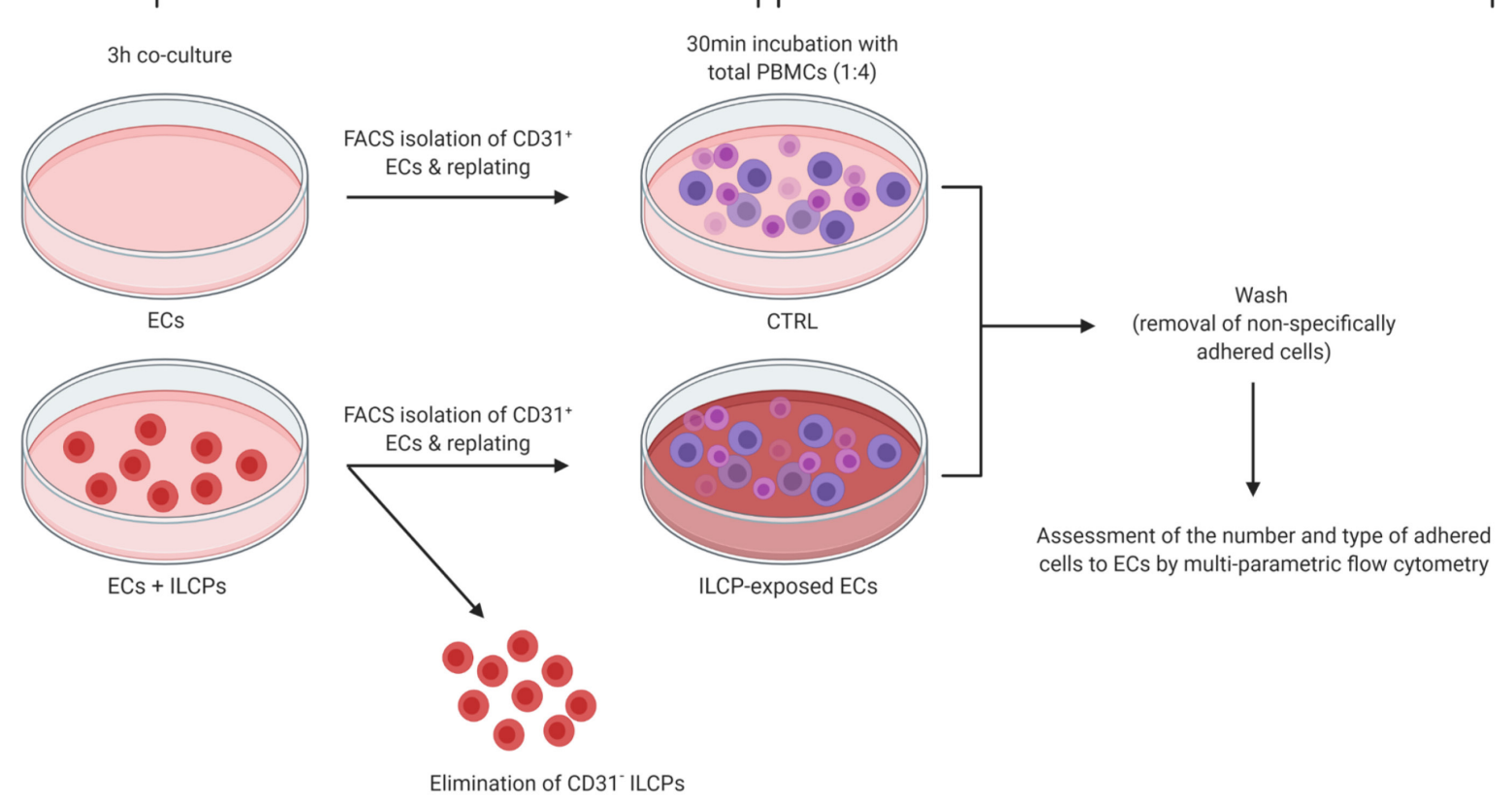

The workflow of the Static Adhesion Assay.

Keywords: Static adhesion, Endothelial cells, Adhesion molecules, Transendothelial migration, Peripheral blood immune cells, Fluorescence-activated cell sorting

[Background] The leukocyte transendothelial migration (TEM) is the outward passage of leukocytes through intact vessel walls into a tissue, and it generally occurs at the endothelial cell-cell junction level (Schimmel et al., 2017). To address the ability of a cell to transmigrate through a monolayer of ECs in vitro, the transwell-based transmigration assays are the most commonly performed (Muller and Luscinskas, 2008). Assays using transwell inserts are very popular due to their simplicity. ECs are grown on top of a polycarbonate filter that separates two fluid compartments. Leukocytes are added to the upper chamber and migrate across the ECs, though the filter, to the lower compartment, where a chemoattractant is generally added. Besides the advantage of allowing to address the ability of a cell to functionally transmigrate through a monolayer of ECs, a few limitations are present: (i) transwell-based assays are extremely expensive; (ii) EC monolayers are difficult to visualize at the microscope, and therefore it is complicated to decide whether to continue or not with the assay. (iii) Transwell-based assays do not allow to investigate cell-cell interactions and mediators of the firm adhesion/arrest step of the TEM process, and so, regulators of the transmigration itself. (iv) Finally, it is really complicated to recover ECs grown on the upper surface of a polycarbonate filter. Conversely, the static adhesion assay is an easy, low cost, and versatile tool, not only to investigate regulators of the transmigration, but also to gain insights into the ability of different cell types to adhere or not to a monolayer of ECs in vitro, 
under static conditions. Moreover, ECs can be collected at the end of the assay and employed in further downstream experiments.

\section{Materials and Reagents}

1. 24-well flat bottom polystyrene plate (Corning, Costar, catalog number: CLS3524)

2. 48-well flat bottom polystyrene plate (Corning, Costar, catalog number: CLS3548)

3. $1.5 \mathrm{~mL}$ Eppendorf tubes

4. $50 \mathrm{~mL}$ Falcon tube

5. $0.22 \mu \mathrm{m}$ filter

6. $75 \mathrm{~cm}^{2}$ Tissue Culture Flasks (TPP, catalog number: TPP 90075)

7. $5 \mathrm{~mL}$ round bottom tubes with snap cap (Corning, Costar, catalog number: 352058 )

8. Human Umbilical Vein Endothelial Cells (HUVEC) (Lonza, catalog number: LZ-CC-2517). Store cryopreserved cells at $-80^{\circ} \mathrm{C}$

9. EGM Endothelial Growth Medium Bullet Kit (Lonza, catalog number: LZ-CC-3124). Once prepared, use the supplemented EGM within 6 weeks. Store at $4^{\circ} \mathrm{C}$ and, each time before use, warm up at $37^{\circ} \mathrm{C}$ only the amount of medium needed.

10. Accutase (Gibco, catalog number: A110501). Store at $4^{\circ} \mathrm{C}$ and warm up at $37^{\circ} \mathrm{C}$ before use.

11. $9 \mathrm{~mL}$ of blood in $\mathrm{Li}$ Heparin tubes from human healthy donors. Process fresh and store the isolated PMBCs at $4^{\circ} \mathrm{C}$ until usage.

12. Lymphoprep (STEMCELL, catalog number: 07851). Store at $4^{\circ} \mathrm{C}$, and let equilibrate at $\mathrm{RT}$ in the dark before use.

13. rhTNF (Peprotech, catalog number: $300-01 \mathrm{~A}$ ). Store at $-20^{\circ} \mathrm{C}$, and avoid multiple thawing/freezing cycles.

14. Distilled water*

*Note: This item can be ordered from any qualified company.

15. Potassium chloride (KCl) (Merck, catalog number: 104936)

16. Potassium dihydrogen phosphate $\left(\mathrm{KH}_{2} \mathrm{PO}_{4}\right)$ (Acros Organics, catalog number: ACRO271080025)

17. Sodium dihydrogen phosphate $\left(\mathrm{NaH}_{2} \mathrm{PO}_{4}\right)$ (VWR Chemicals, catalog number: 28013.264)

18. Sodium chloride ( $\mathrm{NaCl}$ ) (Merck, catalog number: S9625-500G)

19. Sodium hydroxide $(\mathrm{NaOH})$ (Merck, catalog number: $43617-1 \mathrm{~L})$

20. RBC lysis buffer (Invitrogen, catalog number: 00-4333-57). Store at RT.

21. BSA - for FACS buffer (Sigma-Aldrich, catalog number: A7906). Store lyophilized stock at $4^{\circ} \mathrm{C}$.

22. BSA - for Sorting Buffer (Sigma-Aldrich, catalog number: 126609). Store lyophilized stock at $4^{\circ} \mathrm{C}$.

23. Sodium azide pure $\left(\mathrm{NaN}_{3}\right)$ (AppliChem, catalog number: $\left.\mathrm{A} 1430\right)$. Store lyophilized stock at $4^{\circ} \mathrm{C}$.

24. UltraPure 0.5M EDTA, pH 8.0 (Invitrogen, catalog number: $15575-020$ ). Store at $4^{\circ} \mathrm{C}$.

25. Flow cytometry antibodies (store all antibodies at $4^{\circ} \mathrm{C}$ in the dark): 

a. FITC anti-human CD31 (Biolegend, catalog number: $303104-1: 100$ )
b. PE anti-human CD56 (Biolegend, catalog number: $362508-1: 100$ )
c. PE-Cy5 anti-human CD106 (Biolegend, catalog number: $305808-1: 100$ )
d. Pacific Blue anti-human CD54 (Biolegend, catalog number: 353110 - 1:100)
e. $A P C$ anti-human $C D 3$ (BC, catalog number: IM2467-1:100)
f. PE-Cy7 anti-human CD4 (BC, catalog number: $737660-1: 400)$
g. PE-CF594 anti-human CD14 (BD, catalog number: $562335-1: 400)$
h. Alexa Fluor 700 anti-human CD8 (Biolegend, catalog number: $344724-1: 100$ )
i. APC-H7 anti-human CD19 (BD, catalog number: $641395-1: 100)$

26. CountBright Absolute Counting Beads (Thermo Fisher, catalog number: C36950). Store at $4^{\circ} \mathrm{C}$ in the dark

27. $1 \times$ Phosphate Buffer Solution (PBS) (in-house, see Recipes). Store at RT

28. FACS Buffer (see Recipes). Store at $4^{\circ} \mathrm{C}$

29. Sorting buffer (see Recipes). Store at $4^{\circ} \mathrm{C}$

\section{Equipment}

1. Water bath*

2. Centrifuge*

3. BD FACSAria II (BD Biosciences) - or any other fluorescence-activated cell sorter equipped with a blue laser

4. BD LSRFortessa (BD Biosciences) - or any other flow cytometer equipped with the necessary lasers

5. Cell incubator ${ }^{*}\left(5 \% \mathrm{CO}_{2}, 37^{\circ} \mathrm{C}\right)$

6. Autoclave*

*Note: These items can be ordered from any qualified company.

\section{Software}

1. BD FACSDiva ${ }^{\mathrm{TM}}$ (BD Biosciences, v8.0.2, https://www.bdbiosciences.com)

2. FlowJo (Treestar, v10.8.0, https://www.flowjo.com/)

3. Prism (GraphPad v9.2.0, https://www.graphpad.com/)

\section{Procedure}

A. EC culture

1. Thaw cryopreserved ECs at $37^{\circ} \mathrm{C}$ in a water bath, and transfer the cells to a Falcon tube containing $10 \mathrm{~mL}$ of complete EGM. Then, directly transfer the cell suspension to a $75 \mathrm{~cm}^{2}$ flask, and place it in the incubator at $37^{\circ} \mathrm{C}$. 
2. Once the cells have adhered to the flask ( $\sim \mathrm{h}-6 \mathrm{~h}$ later), discard the medium to remove traces of DMSO, and add $10 \mathrm{~mL}$ of fresh medium.

3. Change the medium every 2-3 days and, once confluent, detach ECs with $1 \mathrm{~mL}$ of Accutase at $37^{\circ} \mathrm{C}$ for $5 \mathrm{~min}$.

4. Add $10 \mathrm{~mL}$ of complete EGM, collect the cell suspension, and transfer it to a Falcon tube. Centrifuge at $200 \times g$ for 5 min at RT.

5. Discard the supernatant, resuspend the cell pellet in 1-2 $\mathrm{mL}$ of complete EGM. Count and replate ECs.

Note: For "faster" passaging, seed 8,000-10,000 cells/cm².

6. Use Ecs for functional assays between passages 4 and 6 only.

7. Plate Ecs at $80 \%$ confluency in a 24 -well plate $(\sim 100,000$ cells/well) in $500 \mu \mathrm{L}$ of complete EGM.

B. EC pre-treatment(s)

1. Once the cells are adherent, remove the medium, and wash ECs with $1 \mathrm{~mL}$ of PBS $1 \times$.

2. Incubate ECs with the following culture conditions:

a. Negative control: $500 \mu \mathrm{L}$ of complete EGM only.

b. Positive control: $500 \mu \mathrm{L}$ of complete EGM containing $20 \mathrm{ng} / \mathrm{mL}$ of TNF.

Note: TNF is very well known for being a cytokine that can strongly upregulate the expression of E-Selectin, ICAM-1, and VCAM-1 adhesion molecules on ECs in vitro, thus representing a robust positive control.

c. Experimental setting: $500 \mu \mathrm{L}$ of complete EGM containing ILCPs, at 1:1 ratio.

Note: This protocol can be adapted to any immune cell type of interest and ratios can be adjusted. Please refer to Vanoni et al. (2021) for more details regarding ILCP isolation and culture.

3. Incubate Ecs for $3 \mathrm{~h}$ at $37^{\circ} \mathrm{C}$.

4. After $3 \mathrm{~h}$, discard the supernatant, and perform two washing steps with PBS $1 \mathrm{x}$.

5. Detach ECs by adding $150 \mu \mathrm{L}$ of Accutase and incubate at $37^{\circ} \mathrm{C}$ during $5 \mathrm{~min}$.

6. Add $1 \mathrm{~mL}$ of complete EGM. Transfer the cell suspension to a $5 \mathrm{~mL}$ round bottom tube, and wash with $3 \mathrm{~mL}$ of PBS $1 \times$.

7. Centrifuge the cells at $200 \times g$ for $5 \mathrm{~min}$ at RT.

C. EC sorting

Note: This section is not necessary if you do not incubate ECs with other cell types before performing the static adhesion assay. From Step B7, you can directly go to Step D1.

1. Remove the supernatant, and stain ECs with FITC anti-human CD31 antibody in $50 \mu \mathrm{L}$ of Sorting Buffer. Incubate for 20 min at RT in the dark.

2. Wash the cells by adding $1 \mathrm{~mL}$ of PBS $1 \times$, and centrifuge at $200 \times g$ during $5 \mathrm{~min}$ at RT.

3. Resuspend the cells in $500 \mu \mathrm{L}$ of sorting buffer and proceed with the sorting, according to the manufacturer's instructions and by following the gating strategy shown below (Figure 1). Collect 
the cells in $1.5 \mathrm{~mL}$ Eppendorf tubes containing $500 \mu \mathrm{L}$ of complete EGM.

4. Centrifuge the cells at $200 \times g$ for $5 \mathrm{~min}$, and replate them in a 48 -well flat bottom plate in 250 $\mu \mathrm{L}$ of complete EGM. Leave overnight at $37^{\circ} \mathrm{C}$, or wait until the cells are adherent.
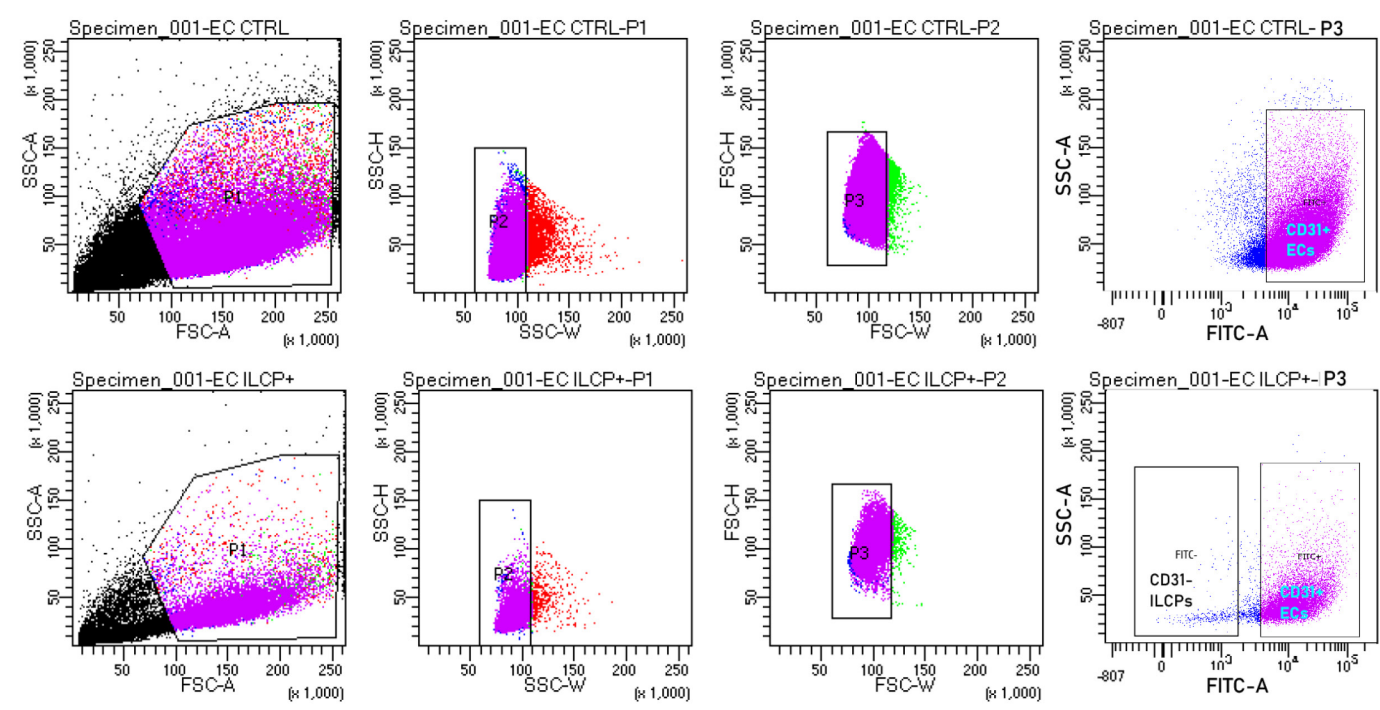

Figure 1. Gating strategy to enrich CD31+ ECs.

Following $3 \mathrm{~h}$ incubation with ILCPs, CD31+ ECs have to be sorted, in order to perform the static adhesion assay without any contaminating CD31- ILCPs. As shown in the SSC-A vs. FITC-A dotplot in panel B, ILCPs themselves adhered to ECs during the in vitro co-culture. To make ECs go through the same steps, also untreated (CTRL) or TNF-treated ECs (not shown) have to be sorted (examples of unstimulated and TNF-stimulated ECs are shown in Figures 2A and $2 \mathrm{~B}$, respectively).

D. Isolation of PBMCs from fresh blood

1. In parallel, in a $50 \mathrm{~mL}$ Falcon tube, dispense $12 \mathrm{~mL}$ of $1.077 \mathrm{~g} / \mathrm{mL}$ Ficoll-Hypaque.

2. In another $50 \mathrm{~mL}$ Falcon tube, transfer the $9 \mathrm{~mL}$ of blood, and add $9 \mathrm{~mL}$ of PBS $1 \times$.

3. Gently transfer the $18 \mathrm{~mL}$ of PBS-diluted fresh blood over the Ficoll-Hypaque solution, being careful to not mix them.

4. Centrifuge at $650 \times g$ during $20 \mathrm{~min}$ at RT, without brake (acceleration/deceleration rate of $9 / 0$ ).

5. Harvest the PBMC layer, and transfer it to a new $50 \mathrm{~mL}$ Falcon tube.

6. Wash the PBMCs with PBS $1 \times$, by filling up to $50 \mathrm{~mL}$.

7. Centrifuge at $450 \times g$ during 5 min at RT, with brake (9/9).

8. Remove the supernatant, and perform a second wash, by filling up to $40 \mathrm{~mL}$.

9. Centrifuge at $200 \times g$ during $10 \mathrm{~min}$ at RT, without brake $(9 / 0)$.

Note: This step will allow platelet removal.

10. Remove the supernatant and incubate the cell pellet with $500 \mu \mathrm{L}$ of RBC lysis buffer during 5 $\min$ at $37^{\circ} \mathrm{C}$.

11. Wash the PBMCs with PBS $1 \times$, by filling up to $50 \mathrm{~mL}$. 
12. Centrifuge at $450 \times g$ during $5 \mathrm{~min}$ at $\mathrm{RT}$, with brake (9/9).

13. Resuspend the cells in culture medium and perform cell counting.

E. Static adhesion assay

Note: In the original protocol from Safuan et al. (2021), the static adhesion assay lasted 5 min. By performing a kinetic experiment, we observed that $30 \mathrm{~min}$ is an optimal incubation period, that allows specific adhesion events to take place.

1. The day after/once ECs have adhered, discard the supernatant and wash the cells with $500 \mu \mathrm{L}$ of PBS 1x.

2. Add freshly isolated PBMCs at $1: 4$ ratio (EC:PBMC) to each well, for $30 \mathrm{~min}$ at $37^{\circ} \mathrm{C}$ in a final volume of $200 \mu \mathrm{L}$ of complete EGM.

3. After $\mathbf{3 0} \mathrm{min}$, discard the supernatant from the wells.

4. Perform two washing steps with $500 \mu \mathrm{L}$ of PBS $1 \times$, to ensure removal of non-adherent cells from the EC monolayer.

5. Detach ECs, together with adherent PBMCs, by incubating them with $200 \mu \mathrm{L}$ of Accutase at $37^{\circ} \mathrm{C}$ for $5 \mathrm{~min}$.

6. Add $1 \mathrm{~mL}$ of complete EGM. Transfer the cell suspension to a $5 \mathrm{~mL}$ round bottom tube and wash with $3 \mathrm{~mL}$ of PBS $1 \times$.

7. Centrifuge the cells at $200 \times g$ during $5 \mathrm{~min}$ at RT.

8. Stain the cells using $50 \mu \mathrm{L}$ of FACS Buffer, for 20 min at RT in the dark, with the antibodies diluted as listed in the Materials and Reagents - Flow Cytometry Antibodies section.

9. In the meantime, let the CountBright Absolute Counting Beads equilibrate at RT.

10. Wash the cells with $2 \mathrm{~mL}$ of PBS $1 \times$ and centrifuge at $450 \times g$ during $5 \mathrm{~min}$ at RT, with brake (9/9).

11. Resuspend the cell pellet in $200 \mu \mathrm{L}$ of FACS buffer.

12. After having set up the flow cytometer, add $20 \mu \mathrm{L}$ of well vortexed (30") CountBright Absolute Counting Beads to the samples, just before acquiring them.

13. Set stopping gate 'beads' at 2000 recorded events.

\section{Data analysis}

1. Once all the samples have been acquired, open your ".fcs" files with FlowJo.

2. After having checked the compensation matrix, draw a gate around the ECs and PBMCs, and visualize the different PBMC subsets according to the gating strategy shown in Figure 2 .

3. Once the analysis is done, export the results (in particular, the column displaying the absolute number of cells contained in each gated population) to an excel file, and copy-paste the number of adhered $\mathrm{CD} 4^{+}$and $\mathrm{CD} 8^{+} \mathrm{T}$ cells, CD14 ${ }^{+}$monocytes, CD19+ $\mathrm{B}$ cells, and CD56 dim/bright pan NK cells to a Prism table, for data visualization.

4. Repeat the experiments at least two times $(2 \times$ positive and negative control - technical 
replicates, and with two different PB healthy donors - biological replicates).

5. Run a paired $t$-test for statistical significance (Prism).

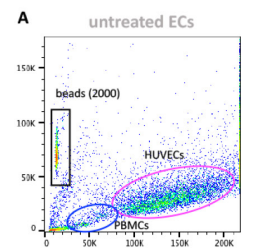

B TNF-stimulated ECs

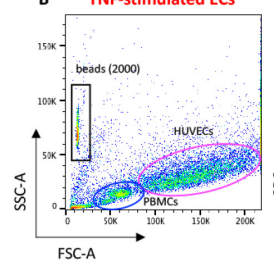

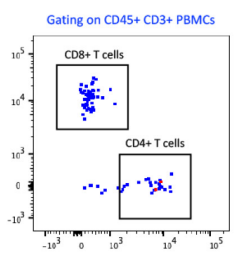

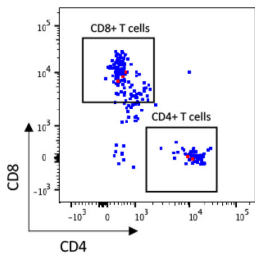

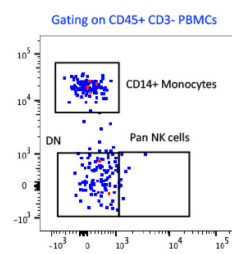

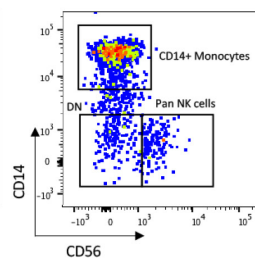

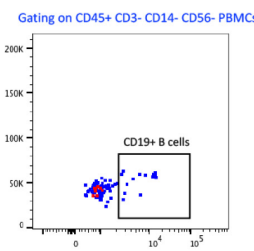
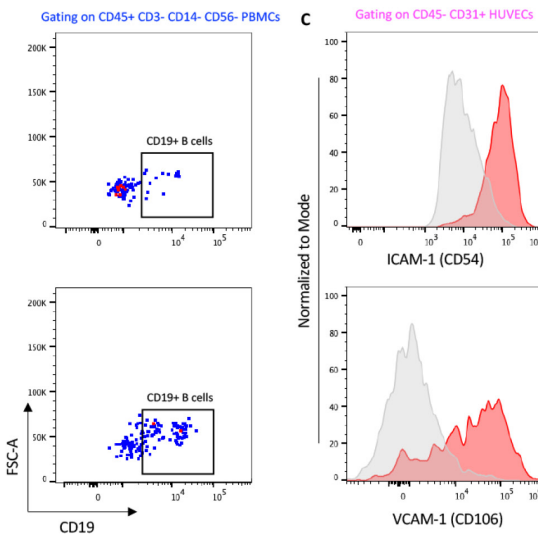

Figure 2. Analysis of the results of the static adhesion assay.

With the use of FlowJo, and according to the used antibody, it is possible to visualize and extract the absolute number of T cells, B cells, Monocytes and NK cells that adhered to ECs in vitro under static conditions. As expected, untreated ECs $(A)$ led to the adhesion of much less PBMCs, if compared to TNF-treated ECs (B), thus defining good positive and negative controls, respectively. Since the assay allows the recovery of ECs, it is possible to investigate, for example, adhesion molecule expression upon different stimulations (C).

\section{$\underline{\text { Notes }}$}

This protocol can be adapted to other cell types rather than ILCPs, in order to evaluate the ability of different immune cell populations/soluble molecules/drugs to influence adhesive properties of ECs in vitro.

\section{Recipes}

1. $1 \times$ PBS (to be filtered over a $0.22 \mu \mathrm{m}$ filter)

Distilled water

$\mathrm{NaCl}$

$\mathrm{KCl}$

$\mathrm{Na}_{2} \mathrm{HPO}_{4}$

$\mathrm{KH}_{2} \mathrm{PO}_{4}$

$\mathrm{NaOH}$

Dissolve the following quantities of salts in $800 \mathrm{~mL}$ of distilled water:

$8 \mathrm{~g}$ of $\mathrm{NaCl}$

$0.2 \mathrm{~g}$ of $\mathrm{KCl}$

$1.44 \mathrm{~g}$ of $\mathrm{Na}_{2} \mathrm{HPO}_{4}$ 
$0.24 \mathrm{~g}$ of $\mathrm{KH}_{2} \mathrm{PO}_{4}$

Adjust $\mathrm{pH}$ to 7.4 with $\mathrm{NaOH}$, filter and autoclave at $121^{\circ} \mathrm{C}$ for $20 \mathrm{~min}$.

Adjust volume to $1 \mathrm{~L}$ with additional distilled water.

2. FACS Buffer - to stain only

PBS $1 \times$

EDTA 5mM

BSA $0.2 \%$

Sodium azide $0.2 \%$

To prepare the buffer for flow cytometry acquisitions, add to $1 \mathrm{~L}$ of PBS $1 \times$ :

$10 \mathrm{~mL}$ of EDTA $0.5 \mathrm{M}$

$2 \mathrm{~g}$ of BSA

$2 \mathrm{~g}$ of sodium azide

3. Sorting Buffer (to be filtered over a $0.22 \mu \mathrm{m}$ filter)

PBS $1 \times$

EDTA $5 \mathrm{mM}$

BSA $0.2 \%$

To prepare the buffer for sorting, add to $1 \mathrm{~L}$ of PBS $1 \mathrm{x}$ :

$10 \mathrm{~mL}$ of EDTA $0.5 \mathrm{M}$

$2 \mathrm{~g}$ of BSA

\section{Acknowledgments}

This work was supported by grants from the Swiss National Science Foundation (PRIMA PR00P3_179727) to CJ; the Swiss Cancer League (KFS-4402-02-2018) to CJ; from a Bourse ProFemmes, University of Lausanne to ST. This work was originally published as a research article in the journal eLife (DOI:10.7554/eLife.58838).

\section{Competing interests}

On behalf of all the authors of the original work, the authors declare no competing financial or nonfinancial interests.

\section{Ethics}

Venous blood was drawn from healthy donors at the local Blood Transfusion Center, Lausanne, Switzerland, under the approval of the Lausanne University Hospital's Institute Review Board. All subjects gave written informed consent in accordance with the Declaration of Helsinki. 


\section{References}

1. Muller, W. A. and Luscinskas, F. W. (2008). Assays of transendothelial migration in vitro. Methods Enzymol 443: 155-176.

2. Safuan, S., Storr, S. J., Patel, P. M. and Martin, S. G. (2012). A comparative study of adhesion of melanoma and breast cancer cells to blood and lymphatic endothelium. Lymphat Res Biol 10(4): 173-181.

3. Schimmel, L., Heemskerk, N. and van Buul, J. D. (2017). Leukocyte transendothelial migration: A local affair. Small GTPases 8(1): 1-15.

4. Vanoni, G., Ercolano, G., Candiani, S., Rutigliani, M., Lanata, M., Derre, L., Marcenaro, E., Schneider, P., Romero, P., Jandus, C. et al. (2021). Human primed ILCPs support endothelial activation through NF-KB signaling. Elife 10: e58838. 